\title{
VIOLÊNCIA NO NAMORO: IMPACTO DE VARIÁVEIS SOCIODEMOGRÁFICAS ACADÉMICAS E AFETIVAS
}

\author{
Paula Nelas \\ Escola Superior de Saúde, Instituto Politécnico de Viseu, UICISA: E \\ pnelas@gmail.com \\ Cláudia Chaves \\ Escola Superior de Saúde, Instituto Politécnico de Viseu, Ci\&DEI \\ claudiachaves21@gmail.com \\ Emília Coutinho \\ Escola Superior de Saúde, Instituto Politécnico de Viseu, UICISA: E \\ ecoutinhoessv@gmail.com \\ João Duarte \\ Escola Superior de Saúde, Instituto Politécnico de Viseu, UICISA: E \\ duarte.johnny@gmail.com
}

Recepción Artículo: 1 enero 2020

Admisión Evaluación: 1 enero 2020

Informe Evaluador 1: 1 enero 2020

Informe Evaluador 2: 1 enero 2020

Aprobación Publicación: 1 enero 2020

\section{RESUMO}

Enquadramento: A violência no namoro é um problema grave, pelas consequências físicas e mentais, pelo impacto nos padrões de relacionamento amoroso futuro e enquanto problema de saúde pública. São objetivos identificar as variáveis sociodemográficas, académicas e afetivas que influenciam a violência no namoro. Tratase de um estudo quantitativo, descritivo-correlacional e transversal, com uma amostra constituída por 429 estu-

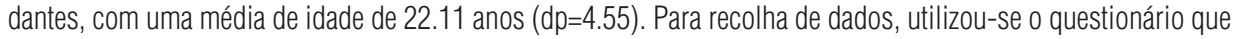
permitiu fazer a caracterização sociodemográfica, académica e afetiva. Foi ainda incluída a Escala de práticas e comportamentos de vitimização na relação de namoro de Dixe, Rodrigues, Freire, Rodrigues, Fernandes e Dias (2010). Apurou-se que 11.9\% é vitima de violência na atual relação de namoro. Os estudantes do sexo masculino, do curso de humanidades e os que já reprovaram, manifestam práticas e comportamentos de vitimização mais frequentes, com diferenças estatisticamente significativas $(p<0.05)$. Os que referem hábitos tabágicos revelam práticas e comportamentos de vitimização mais frequentes $(p<0.05)$. Os estudantes que já iniciaram a vida sexual, que admitem ser vítima de violência na atual relação de namoro, os que já foram vítimas de violência em relações de namoro anterior, os que não têm uma boa relação familiar e não possuem uma boa relação com os amigos, manifestam práticas e comportamentos de vitimização mais frequentes $(p<0.05)$.

Recomendamos implementar, nas escolas, ações de sensibilização para comportamentos e práticas de violência no namoro, envolvendo neste âmbito toda a comunidade (estudantes, família e academia). Gabinetes de 


\section{VIOLÊNCIA NO NAMORO: IMPACTO DE VARIÁVEIS SOCIODEMOGRÁFICAS ACADÉMICAS E AFETIVAS}

apoio à vitima, em contexto de academia, também devem ser pensados e estruturados com apoio psicológico e social.

Palavras chave: vitimização; namoro; práticas, afetos; sociodemografia

\section{ABSTRACT}

Dating violence: Impact of academic, affective and sociodemographic variables. Violence in dating is a serious problem, due to its physical and mental consequences, its impact on the patterns of future love relationships and as a public health problem. The objectives are to identify the sociodemographic, academic and affective variables that influence dating violence. This is a quantitative, descriptive-correlational and cross-sectional study, with a sample of 429 students, with an average age of 22.11 years ( $S D=4.55)$. For data collection, a questionnaire was used that allowed the sociodemographic, academic and affective characterization to be carried out. The Scale of victimization practices and behaviors was also included in the dating relationship of Dixe, Rodrigues, Freire, Rodrigues, Fernandes and Dias (2010). In terms of results, it was found that $11.9 \%$ are victims of violence in the current dating relationship. Male students, from the humanities course and those who have already failed, show more frequent victimization practices and behaviors, with statistically significant differences ( $p$ $<0.05)$. Those who report smoking habits reveal more frequent victimization practices and behaviors $(p<0.05)$. Students who have already started sexual life, who admit to being a victim of violence in the current dating relationship, those who have been victims of violence in previous dating relationships, those who do not have a good family relationship and do not have a good relationship friends, manifest more frequent victimization practices and behaviors $(p<0.05)$. We recommend implementing in schools, actions to raise awareness of behaviors and practices of violence in dating, involving in this scope the whole community (students, family and academy). Victim support offices, in the context of academia, should also be designed and structured with psychological and social support.]

Keywords: victimization; dating; practices, affections; sociodemography

\section{INTRODUÇÃO}

A World Health Organization (2016), refere que a violência no namoro se refere a todo o comportamento que pode causar dano físico, sexual ou psicológico, abrangendo os casos de agressão física, a coação sexual, maltrato psicológico e comportamentos dominantes, sendo que este tipo de violência ocorre principalmente a partir da adolescência. Esta realidade está presente em várias partes do mundo e tem consequências imediatas e tardias para a saúde das vítimas (Barros \& Schairber, 2017). Assim, a violência no namoro é um problema de saúde em diferentes partes do mundo e uma das principais questões a ser enfrentada.

Vários estudos mostram problemas de saúde associados à violência no namoro, incluindo a depressão, a ansiedade e 0 abuso de álcool e outras substâncias nocivas (Leen, Sorbring, Mawer, Holdsworth, Helsing \& Bowe, 2013). Outros autores apontam o comportamento sexual de risco e 0 baixo desempenho académico como consequências negativas (Barros, Schraiber \& França-Junior, 2011). Além disso, há evidências de que a violência em outros contextos, como na família e na vizinhança, pode estar relacionada com a violência no namoro (Centers for Disease Control and Prevention, 2016).

Perante esta problemática, a World Health Organization (2016), recomenda a implementação de programas focados na prevenção primária em detrimento de programas de prevenção secundária, nos quais os jovens devem ser alertados para esta problemática, devendo também ser dada atenção à prevenção da vitimização de jovens e à violência simbólica, no que se refere às desigualdades de género. Nestes programas deve ser ainda dada relevância à promoção do bem-estar da pessoa, família e sociedade.

Naturalmente, várias políticas e programas de ação têm sido implementados, especialmente em contexto escolar, sendo este o principal espaço de socialização dos adolescentes. Não obstante, a questão ainda é incipientemente discutida e 0 conhecimento existente, neste âmbito, dificulta a sensibilização para 0 problema e a respetiva formulação de políticas para o resolver (Taquette \& Monteiro, 2019). 
A violência no namoro ocorre quando a relação de casal está mais solidificada e oficializada, é nesta fase que os casais se conhecem melhor e pensam que um ato violento foi apenas um ato isolado (Dixe, Rodrigues, Freire, Fernandes \& Dias, 2010). A presença de violência no namoro contraria a crença de que esta deveria ser a melhor fase da vida dos jovens. Importa reforçar que a violência é definida como a ameaça ou o uso intencional da força ou do poder e abrange atos de agressão física, psicológica e sexual, alicerçados em conceções sociais e culturais estereotipadas (Ventura, Frederico-Ferreira \& Magalhães, 2013).

Segundo a Associação Portuguesa de Apoio à Vítima (2016), a violência no namoro divide-se em cinco tipologias. A violência física, que se baseia no grau de ameaça à vida da vítima, com recurso à força física ou à restrição, tendo como principal finalidade causar dor ou injúria à vítima (Félix, 2012). A violência sexual, na qual se incluem forçar as práticas de atos sexuais ou de carícias do foro sexual, sem a vontade e 0 consenso do parceiro (Associação Portuguesa de Apoio à Vítima, 2016). A violência verbal, que se caracteriza por gritar e humilhar 0 parceiro através de críticas e comentários negativos, intimidar ou ameaçar (Ferreira, 2013). A violência psicológica, onde se incluem formas de danificar objetos pessoais, controlar o dia-a-dia do parceiro e/ou ameaçar terminar a relação como forma de manipulação (Associação Portuguesa de Apoio à Vítima, 2016). A violência psicológica pode ser definida pelo recurso de comunicação verbal e não-verbal de forma a amedrontar 0 outro membro da relação ou mesmo causar-Ihe sofrimento. Este tipo de violência, para Gonçalves (2013), compreende a coerção, a intimidação, 0 isolamento, entre diversos outros tipos de controlo. Na violência social, o(a) namorado(a) proíbe o contacto com familiares e amigos, humilha, envergonha, ou tenta denegrir a imagem do parceiro perante terceiros, e/ou mexe, sem o devido consentimento, em contas eletrónicas, redes sociais ou equipamento eletrónico (Associação Portuguesa de Apoio à Vítima, 2016).

Na atualidade, surgiu um outro tipo de violência no namoro, a denominada violência stalking, ou seja, a perseguição, que se caracteriza por um alvo (vitima), que pode ser potenciador de um comportamento de assédio constante, através da comunicação, vigilância e monitorização de uma pessoa, com impacto negativo e muitas vezes severo para as vítimas. Esta forma de violência é particularmente preocupante, uma vez que pode afetar qualquer pessoa, independentemente do sexo, orientação sexual, etnia, faixa etária ou classe social, sendo os jovens adultos referenciados como os mais vulneráveis (Ferreira, 2013).

Com base numa revisão sistemática da literatura, Taquette e Monteiro (2019) verificaram que, em 35 artigos analisados, há uma prevalência de violência no namoro superior a 50\% em ambos os sexos, tanto como vítimas, tanto como agressores, com consequências mais graves para as raparigas. Três núcleos temáticos principais foram identificados nos estudos: vulnerabilidades relacionadas com a violência no namoro, circularidade da violência e problemas de saúde associados à violência no namoro. Os dados indicam que a violência no namoro está profundamente enraizada na cultura patriarcal e é mais frequente em associação à heterossexualidade e a ambientes mais desfavoráveis em termos socioculturais. Ocorre de forma circular e está ligada a outras formas de violência em diferentes contextos (família, escola, comunidade e meios de comunicação social), resultando em problemas de saúde como a depressão, a ansiedade, a baixa autoestima, o consumo abusivo de álcool e drogas e a sexo desprotegido.

Em suma, os estudos revelam que a violência no namoro é um grave problema social, com graves consequências, sendo importante difundir a noção de vitimização por violência no namoro aos jovens e informá-los sobre a complexidade das muitas maneiras de entender a vitimização.

\section{OBJETIVOS DA INVESTIGAÇÃO}

São objetivos, identificar as variáveis sociodemográficas, académicas e afetivas que influenciam a violência no namoro.

\section{AMOSTRA E PARTICIPANTES}

Trata-se de uma amostra não probabilística por conveniencia, constituida por 429 estudantes do ensino superior, com uma média de idade de 22.11 anos ( $d p=4.55)$. 


\section{VIOLÊNCIA NO NAMORO: IMPACTO DE VARIÁVEIS SOCIODEMOGRÁFICAS ACADÉMICAS E AFETIVAS}

\section{METODOLOGIA E INSTRUMENTOS UTILIZADOS}

Trata-se de um estudo quantitativo, transversal, descritivo e correlacional. 0 instrumento de colheita de dados foi um questionário, que permitiu fazer a caracterização sociodemográfica, académica e afetiva. Foi ainda incluída a Escala de práticas e comportamentos de vitimização na relação de namoro de Dixe, Rodrigues, Freire, Rodrigues, Fernandes e Dias (2010). Foram respeitados os procedimentos éticos e legais relativos à aplicação e análise dos dados. 0 instrumento de cálculo foi o Statistical Package for the Social Sciences (SPSS), na versão 24.0 para Windows.

\section{RESULTADOS}

Constata-se que a grande maioria dos estudantes é de nacionalidade portuguesa (94.6\%). Há um predomínio de participantes que residem em zona urbana (60.1\%). Verifica-se que $50.1 \%$ coabitam com A família nuclear, $45.5 \%$ com amigos/outras pessoas e 4.4\% com família monoparental. Em relação ao rendimento do agregado familiar, 37.1\% referem >1000 $\leq 1500$ euros, em 35.4\% o agregado familiar tem um rendimento de $>500 \leq 1000$ euros, e $21.9 \%$ mencionam que o rendimento do seu agregado familiar é $>1500$ euros.

Quanto ao curso que frequentam, o mais prevalecente é 0 da área da saúde (63.4\%). Relativamente ao ano de licenciatura prevalecem os estudantes no $3^{0}$ ano $(34.7 \%)$. A maioria (72.7\%) refere não ter reprovado.

Verificando-se que a maioria dos participantes (84.1\%) já iniciou a vida sexual. Mais de metade da amostra (62.9\%) namora atualmente. Dos que namoram na atualidade, 37.8\% namoram há 2-3 anos, 32.6\% há 4 ou mais anos e 29.6\% mantêm essa relação de namoro $\leq 1$ ano.

Procurou-se saber se os participantes já foram vítimas de violência no namoro, constatando-se que a grande maioria (89.7\%) refere que não, com $10.3 \%$ a admitirem que sim. Quanto ao facto de ser vítima de violência na atual relação de namoro, constata-se que maioritariamente relatam que não (88.1\%), no entanto 11.9\% confirmam que são vítimas de violência no atual namoro.

Quanto ao local onde ocorreu a violência em anteriores relações de namoro, constata-se que $50.7 \%$ referem que ocorreu em casa. Em $40.3 \%$ dos casos, a violência ocorreu na faculdade. Verifica-se que em $6.0 \%$ esta ocorreu no local de trabalho. Regista-se que $47.8 \%$ referem que eram vítimas de violência na rua. Em $16.4 \%$ dos casos, os participantes eram vítimas de violência em estabelecimentos públicos. Para $38.8 \%$ a violência ocorria online.

Foi questionado, aos participantes vítimas de violência no namoro em relações anteriores, a quem pediam ajuda, tendo $31.3 \%$ referido os familiares. Verifica-se que $50.7 \%$ pediram ajuda aos amigos. Já $11.9 \%$ solicitou ajuda ao psicólogo. Apenas $5.1 \%$ dos participantes pediu ajuda à polícia. Os participantes, vitimas de violência em relações de namoro anterior, relatam que 0 (a) agressor(a) não os incomoda atualmente (95.5\%).

Questionou-se ainda se alguma vez observaram algum tipo de violência no namoro, constatando-se que a maioria (54.0\%) confirma. Os que admitem já ter observado algum tipo de violência no namoro, a maioria (56.4\%) refere que foi de controlo, seguindo-se a violência psicológica (26.5\%).

A análise dos resultados referentes à relação entre a violência no namoro em função do género revela que, na globalidade, são os participantes do sexo masculino que manifestam mais este comportamento, sobretudo a violência stalking ( $(=0.008)$. De igual modo, observamos significância estatística para a violência psicológica $(\mathrm{p}=0.032)$. Relativamente à idade, residência, coabitação e rendimento familiar não encontramos relevância estatisticamente significativa.

Verifica-se que os participantes do curso de humanidades pontuam mais na violência física e sexual ( $p=0.008$ ) e para a violência psicológica ( $p=0.040$ ) são os participantes da área de engenharias, verificando-se para os dois casos relevância estatística. Constata-se que participantes que frequentarem 0 2.. ano do curso revelam valores de ordenação média mais elevados na violência física e sexual e na violência stalking, enquanto os do 4.. ano pontuam mais na violência psicológica, mas sem relevância estatisticamente significativa entre os grupos. Também são os participantes que já reprovaram que apresentam pontuações mais elevadas nas dimensões de violência em análise, com diferenças estatisticamente significativas, excetuando na violência psicológica. 
Os participantes que admitem já ter iniciado a vida sexual pontuam mais em todas as dimensões da violência no namoro, com relevância estatisticamente significativas em todas as dimensões da violência (violência física e sexual, violência psicológica e stalking) com valor de $p=0.000$.

Os que admitem ser vítima de violência na atual relação de namoro pontuam mais em todas as dimensões da violência (violência física e sexual $p=0.001$, violência psicológica $p=0.014$ e stalking $p=0.000$ ). 0 facto de já ter sido vitima de violência no namoro em ralações anterior também revela significância estatística para a violência física e sexual ( $p=0.001)$, violência psicológica $(p=0.000)$ e stalking ( $p=0.000)$.

Quanto à relação entre a violência no namoro em função de existir violência doméstica na família, verificamos

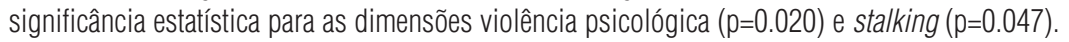

Os participantes que admitem não ter uma boa relação com os amigos manifestam pontuações mais elevadas, indicando práticas e comportamentos de vitimização mais frequentes, destacando-se a violência física e sexual ( $p=0.005)$, violência psicológica ( $p=0.002)$ e stalking ( $p=0.005)$.

0 facto de namorar na atualidade, o tempo da relação de namoro, assim como o facto de ter alguma vez ter observado algum tipo de violência no namoro não revelaram significância estatística.

\section{DISCUSSÃO}

Procurou-se saber se os participantes já foram vítima de violência no namoro, constatando-se que a maioria refere que não (89.7\%), com 10,3\% a admitirem que já foram vítimas. Quanto a ser vítima de violência na atual relação de namoro, $11.9 \%$ atestam. Estes resultados confirmam os apurados no Estudo Nacional sobre Violência no Namoro de 2019, com uma amostra de 4938 jovens de todos os distritos do País (Portugal continental e arquipélagos dos Açores e Madeira). Do total de participantes, $70 \%$ afirmaram estar ou já terem estado num relacionamento amoroso, de namoro ou ocasional e $67 \%$ do total dos jovens, incluindo ambos os sexos, legitimam pelo menos um comportamento de violência no namoro, sendo o tipo de violência mais legitimado o controlo (27\%), seguido da perseguição (24\%), da violência sexual (24\%), da violência através das redes sociais (23\%), violência psicológica (16\%) e a violência física (9\%) segundo Magalhães, (Coord. (2020). Estes autores verificaram ainda que 19,1\% relataram terem sido vítima de violência em relações de namoro anterior. Destes, sobressaem os que foram vítima de controlo (77.6\%), e os que foram vítima de violência psicológica (70.1\%). Verifica-se também que 31.3\% foram vítima de perseguição. Quanto à violência nas redes sociais, regista-se que em $13.4 \%$ esta ocorreu, com destaque para o sexo feminino (13.6\%). É de referir que $23.9 \%$ foi vítima de violência física e $35.6 \%$ dos participantes do sexo feminino foi vítima de perseguição.

Segundo o estudo do Observatório da Violência no Namoro, de Neves, Jamal, Peixoto \& Borges (2021), em maio de 2020, dos 284 casos de violência no namoro reportados, $11.6 \%$ das vítimas correram risco de vida, $89.7 \%$ das vítimas de violência são do género feminino e os agressores são jovens homens (91.9\%), com uma média de idades de 25 anos. Em 46.8\% dos casos, os agressores ainda namoram com as vítimas. Ainda segundo os dados recolhidos por Neves, Jamal, Peixoto \& Borges (2021), das 284 denúncias recebidas, 140 foram feitas por ex-vítimas, 115 por testemunhas e 29 por atuais vítimas. As vítimas de violência são quase na sua totalidade do género feminino (89.7\%), tal como constatado no presente estudo. A mesma fonte indica que as tipologias de violência mais significativas, em conformidade com as denúncias efetuadas, foram a violência psicológica (84.5\%), a violência emocional (82\%), a violência verbal (80.3\%), seguida da perda de controlo (63.7\%). A violência física foi referida em $48.6 \%$ das situações, seguida da violência social (35.6\%), perseguição (32.7\%) e depois a violência sexual (22.5\%).

Quanto ao local onde ocorreu a violência em anteriores relações de namoro, constata-se que 50.7\% ocorreu em casa, $40.3 \%$ ocorreu na faculdade, $47.8 \%$ refere a rua, $16.4 \%$ em estabelecimento público e $38.8 \%$ reportam a violência online. Estes resultados estão em conformidade com os dados encontrados por Neves, Jamal, Peixoto \& Borges (2021), uma vez que ficou demonstrado que o local de maior incidência da violência é a casa (69.7\%), seguido da rua (51.8\%), estabelecimento público (32\%) e escola/faculdade (26.4\%) e, em 27.5\% a violência relatada foi online, o que acontece ao longo do dia, o que também foi verificado no presente estudo, pois a maio- 


\section{VIOLÊNCIA NO NAMORO: IMPACTO DE VARIÁVEIS SOCIODEMOGRÁFICAS ACADÉMICAS E AFETIVAS}

ria dos participantes vítimas de violência na atual relação de namoro referem que essa situação ocorre ao longo de vários momentos do dia.

Os participantes vítimas de violência no namoro em anteriores relações, pediam ajuda maioritariamente (50.7\%) aos amigos e $31.3 \%$ aos familiares. De igual modo, dos 5 participantes vítimas de violência na atual relação de namoro, três pediu ajuda a familiares, um pediu ajuda aos amigos e outro a familiares e psicólogo.

No presente estudo, os participantes que foram vítimas de violência em relações de namoro anterior relatam que 0(a) agressor(a) não os incomoda atualmente (95.5\%). Os dados de Neves, Jamal, Peixoto \& Borges (2021), dizem que em $46.8 \%$ dos casos, os agressores ainda namoram com as vítimas.

Questionaram-se os participantes se alguma vez observaram algum tipo de violência no namoro, a maioria (54.0\%) confirma, o que corrobora a existência de elevadas taxas de violência no namoro, confirmado pelo Estudo Nacional sobre Violência no Namoro de Magalhães (Coord. (2020) e por Neves, Jamal, Peixoto \& Borges (2021).

A maioria (76.9\%) refere que não existe ou nunca existiu algum tipo de violência doméstica na família, mantendo, maioritariamente (93.9\%), uma boa relação familiar e uma boa relação com os amigos (99.5\%). Duarte (2019) refere que a família é encarada quer como um meio para fomentar condutas agressivas, quer para interiorizar determinados valores ideológicos e sociais. A autora, menciona que os jovens que testemunharam violência matrimonial na infância parecem revelar uma maior pré-disponibilidade de perpetrar e/ou sofrer de vitimização nas suas relações de intimidade, porém com efeitos mínimos.

No que diz respeito às variáveis sociodemográficas e académicas que interferem na violência no namoro, apurou-se que o sexo, o curso e o insucesso escolar revelaram significância estatística. Apurou-se que os participantes do sexo masculino, do curso de humanidades e os que reprovaram manifestaram práticas e a comportamentos de vitimização mais frequentes.

Constatou-se que os participantes que já iniciaram a vida sexual, que admitem ser vítima de violência no atual namoro, os que já foram vítima de violência em relações de namoro anterior, aqueles que não têm uma boa relação familiar e não possuem uma boa relação com os amigos são os que manifestam práticas e comportamentos de vitimização mais frequentes. Neste âmbito, o Centers for Disease Control and Prevention (2016) refere que há evidências de que a violência em outros contextos, como na família e na vizinhança, pode estar relacionada com a violência no namoro. Também Korkmaz \& Överlien (2020) estudaram a violência no namoro/violência pelo parceiro íntimo em jovens na faixa etária dos 17-23 anos, as consequências e riscos para as respostas face ao evento e resiliência. No geral, os dados mostram que muito jovens são resilientes perante a violência e consideram normal o comportamento violento do(a) namorado(a).

\section{CONCLUSÕES}

Perante os resultados, e tal como preconizado pela World Health Organization (2016), recomendamos a implementação de programas cujo foco seja a prevenção primária. No âmbito desta sensibilização, os jovens devem ser alertados para a problemática da violência do namoro, devendo ser dada atenção à prevenção da vitimização e à violência simbólica, no que se refere às desigualdades de género.

Para levar a cabo estes programas de prevenção primária, considera-se importante apostar em campanhas de sensibilização nas instituições escolares, desde 0 ensino básico até ao ensino superior, desmistificando crenças relacionadas com a violência no namoro e promovendo intervenções que demonstrem as consequências que a violência no namoro tem no bem-estar psicológico. Será também importante que se façam debates sobre atitudes que legitimam a violência e se alerte para a importância de pedido de ajuda profissional caso sejam vítimas de violência.

Deve igualmente alertar-se para o facto de que a violência no namoro em adolescentes não deve ser tratada da mesma forma que a violência em casais adultos, pois, embora certamente compartilhe semelhanças, o facto de ocorrer entre os adolescentes torna-a diferente, não só pelos efeitos que tem no desenvolvimento dos adolescentes, como também no impacto que tem em relações afetivas futuras. 


\section{REFERÊNCIAS BIBLIOGRÁFICAS}

Associação Portuguesa de Apoio à Vítima. (2016). Estatísticas APAV: Relatório anual de 2015. Lisboa: APAV.

Barros, C. R. S, \& Schairber, L. B. (2017). Intimate partner violence reported by female and male users of healthcare units I. Revista Saude Pública, 51(7). Doi: 10.1590/S1518-8787.2017051006385.

Barros, C., Schraiber, L. B., França-Junior, I. (2011). Association between intimate partner violence against women and HIV infection. Revista Saúde Pública, 45(2), 365-372.

Centers for Disease Control and Prevention. (2016). Injury prevention and control division of violence prevention understanding teen dating violence. Acedido em https://www.cdc.gov/violenceprevention/pdf/teen-datingviolence-factsheet-a.pdf.

Dixe, M. A. C. R., Rodrigues, A. L., Freire, C., Rodrigues, G., Fernandes, M., \& Dias, T. (2010). A violência de género na relação de namoro em estudantes do ensino superior: Práticas e comportamentos de violência (pp. 1589-1599). In Actas do VII Simpósio Nacional de Investigação em Psicologia. Braga: Universidade do Minho.

Duarte, C. R. S. da (2019). Violência no namoro: Taxa de incidência em estudantes universitários (Dissertação de Mestrado, Universidade Fernando Pessoa, Porto). Acedido em https://bdigital.ufp.pt/bitstream/10284/8315/1/PG_Catarina\%20Duarte.pdf

Félix, D. (2012). Crenças de legitimação da violência de género e efeitos de campanhas de prevenção: um estudo exploratório (Dissertação de mestrado, Faculdade de Psicologia, Universidade de Lisboa). Acedido em http://repositorio.ul.pt/handle/10451/6891

Ferreira, J. P. (2013). Stalking como forma de violência nas relações de namoro (Dissertação de mestrado, Instituto Superior de Ciências da Saúde Egas Moniz). Acedido em http://comum.rcaap.pt/handle/123456789/6243

Gonçalves, M. A. S. (2013). Namoro na adolescência: Atitudes de legitimação de violência estratégias de resolução de conflitos em adolescentes nos Açores (Dissertação de Mestrado, Universidade dos Açores). Acedido

em http://repositorio.uac.pt/bitstream/10400.3/2770/1/DissertMestradoMonicaAndreiaSilvaGoncalves2013.pdf

Korkmaz, S., \& Överlien, C. (2020). Responses to youth intimate partner violence: The meaning of youth-specific factors and interconnections with resilience. Journal of Youth Studies, 23(3), 371-387. Doi: 10.1080/13676261.2019.1610557.

Leen, E., Sorbring, E., Mawer, M., Holdsworth, E., Helsing, B., \& Bowen, E. (2013). Prevalence, dynamic risk factors and the efficacy of primary interventions for adolescent dating violence: An international review. Aggression and Violent Behavior, 18(1), 159-174. http://dx.doi.org/10.1016/j.avb.2012.11.015

Magalhães, M. J. (Coord.). (2020). Estudo nacional sobre a violência no namoro: 2019. Lisboa: UMAR - União de Mulheres Alternativa e Resposta. Acedido em http://www.umarfeminismos.org/images/stories/noticias/Estudo_Nacional_VN_2019_da_UMAR.pdf

Neves, S., Jamal, S., Peixoto, S., \& Borges, J. (2021). Observatório da violência no namoro: Resultados 2020. Acedido em https://www.cig.gov.pt/area-portal-da-violencia/violencia-no-namoro/documentacao/

Taquette, S. R., \& Monteiro, D. L. M. (2019). Causes and consequences of adolescent dating violence: a systematic review. Journal of Injury \& Violence Research, 11(2), 137-147. https://doi.org/10.5249/jivr.v11i2.1061

Ventura, M., Frederico-Ferreira, M., \& Magalhães, M. (2013). Violência nas relações de intimidade: Crenças e atitudes de estudantes do ensino secundário. Revista de Enfermagem Referência, 3(11), 95-103.

World Health Organization. (2016). FAQ on health and sexual diversity: An introduction to key concepts. Geneva: WHO. Acedido em https://www.who.int/gender-equity-rights/news/20170329-health-and-sexual-diversityfaq.pdf

Young, B. J., Furman, W., \& Jones, M. C. (2012). Changes in adolescents' risk factors following peer sexual coercion: Evidence for a feedback loop. Development and psychopathology, 24(2), 559-571. Acedido em https://doi.org/10.1017/S0954579412000168 
